\title{
Molar Incisor Hypomineralization - Review and Recommendations for Management
}

\section{Megha Chawla $^{1 *}$, Saumya Paul ${ }^{1}$, Bhavna Gupta Saraf ${ }^{2}$, Neha Sheoran ${ }^{3}$ and Vishal Juneja ${ }^{4}$}

${ }^{1}$ PG Student, Department of Paedodontics and Preventive Dentistry, Sudha Rustagi

College of Dental Sciences and Research Institute, Faridabad, Haryana, India

${ }^{2}$ Head of Department, Department of Paedodontics and Preventive Dentistry, Sudha

Rustagi College of Dental Sciences and Research Institute, Faridabad, Haryana, India

${ }^{3}$ Professor, Department of Paedodontics and Preventive Dentistry, Sudha Rustagi

College of Dental Sciences and Research Institute, Faridabad, Haryana, India

${ }^{4}$ Reader, Department of Oral Anatomy, Sudha Rustagi College of Dental Sciences and Research Institute, Faridabad, Haryana, India

*Corresponding Author: Megha Chawla, PG Student, Department of Paedodontics and Preventive Dentistry, Sudha Rustagi College of Dental Sciences and Research Institute, Faridabad, Haryana, India.

DOI: $10.31080 /$ ASDS.2020.04.0780

\author{
Received: January 18, 2020 \\ Published: February 10, 2020 \\ (C) All rights are reserved by Megha Chawla., \\ et al.
}

\begin{abstract}
Molar incisor hypo mineralization (MIH) portrays clinical image of hypo mineralization of fundamental birthplace influencing at least one first permanent molars (FPMs) that are related oftentimes with influenced incisors. Etiological relationship with fundamental conditions or ecological conditions during the youngster's initial 3 years has been ensnared. The perplexing consideration engaged with treating influenced youngsters must address their conduct and uneasiness that plans to give a strong rebuilding under torment free conditions. The difficulties incorporate sufficient sedation, appropriate pit plan, and decision of helpful materials. Rebuilding efforts in hypo mineralized molars seem to flop oftentimes; there is little proof based writing to encourage clinical choices on whole plan and material decision. A 6-advance way to deal with the executives is portrayed: (1) hazard recognizable proof; (2) early conclusion; (3) remineralisation and desensitization; (4) avoidance of caries and post eruption breakdown; (5) reclamations and extractions; and (6) upkeep. The high predominance of MIH demonstrates that there is requirement for research to explain etiological factors and improve the sturdiness of rebuilding efforts in influenced teeth. The motivation behind this review was to depict the degrees of MIH, pervasiveness, putative etiological factors, and highlights of hypo mineralized veneer in molar incisor hypo mineralization and to display a consecutive way to deal with the board of this.
\end{abstract}

Keywords: FPMs: First Permanent Molars; MIH: Molar Incisor Hypo mineralization; ART: Atraumatic Restorative Treatment; PEB: Post Eruptive Breakdown; SEM: Scanning Electron Microscopy; LM: Light Microscopy

Molar incisor hypo mineralization

Definition

In 2001 Weerheijm and collaborators presented the term Molar Incisor Hypo mineralization (MIH) to portray the clinical nearness of a subjective polish formative imperfection of foundational inception that influences the FPMs and once in a while the incisors
[1-3]. This definition is currently broadly utilized and has been adjusted by scientists and clinicians to depict MIH. Be that as it may, in light of the definition alone, it isn't constantly conceivable to arrange (analyse) influenced FPMs with MIH. Hypo mineralization might be random to MIH, one model being the diffuse opacities found in fluorotic veneer. 
Molar Incisor Hypo mineralization is characterized as the clinical appearance of morphological finish deserts including the occlusal or potentially incisal third of at least one lasting molars or incisors as result as "hypo mineralisation of foundational origin."(Weerheijm., et al. 2003).

\section{Levels of MIH}

\section{Mild MIH}

Demarcated opacities are in non-stress-bearing areas of FPM Isolated opacities No enamel loss from fracturing is present in opaque areas No history of dental hypersensitivity No caries associated with the affected enamel Incisor involvement is usually mild if present.

\section{Moderate MIH}

Intact atypical restorations Demarcated opacities are present on occlusal/incisal third of teeth without post eruptive enamel breakdown. Post eruptive enamel breakdown/ caries are limited to 1 or 2 surfaces without cuspal involvement Dental sensitivity is generally reported as normal esthetic concerns.

\section{Severe MIH}

Post eruptive enamel breakdown History of dental sensitivity Widespread caries is associated with the affected enamel Crown destruction can readily advance to involve the dental pulp Defective atypical restoration is present Aesthetic concerns are expressed by the patient or parent.

\section{Aetiological considerations}

- Environmental conditions.

- Respiratory tract infections.

- Perinatal complications.

- Dioxins.

- Oxygen starvation and low birth weight.

- Calcium and phosphate metabolic disorders.

- Childhood diseases.

- Antibiotics.

- $\quad$ Prolonged breast-feeding.

\section{Clinical implications}

MIH presents a set of problem that may require a multi-disciplinary approach for management. Depending on the severity patients affected by MIH may present several clinical problems, including:
- $\quad$ Rapid wear,

- Enamel loss,

- Increased susceptibility to caries,

- $\quad$ Sensitivity, and Dental fear and anxiety associated with pain [4].

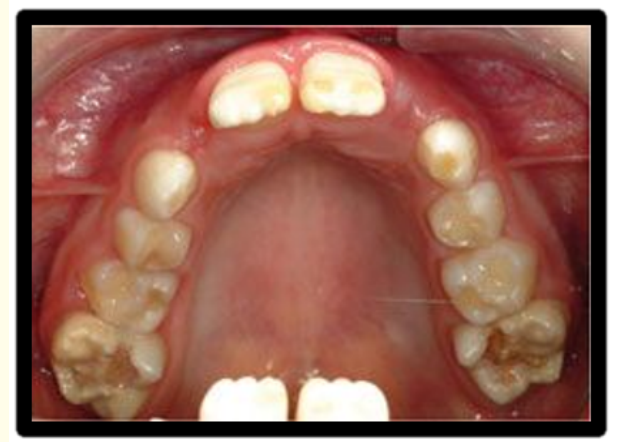

Figure 1

\section{Clinical management}

(A Clinical Management Approach for Permanent First Molars Affected by Molar Incisor Hypo mineralization) [5,6] By William., et al. 2006.

\begin{tabular}{|l|c|}
\hline Steps & Recommended Procedures \\
\hline Risk identification & $\begin{array}{c}\text { Assess medical history for putative etio- } \\
\text { logical factors }\end{array}$ \\
\hline Early diagnosis & $\begin{array}{c}\text { Examine at risk molars on radiograph } \\
\text { if possible Monitor these teeth during } \\
\text { eruption }\end{array}$ \\
\hline $\begin{array}{l}\text { Remineralisation } \\
\text { and desensitization }\end{array}$ & Apply localized topical fluorides \\
\hline tal caries and PEB & $\begin{array}{c}\text { Institute through oral hygiene home } \\
\text { care program Reduce cariogenicity and } \\
\text { erosivity of diet Place pit and fissure } \\
\text { sealants }\end{array}$ \\
\hline $\begin{array}{l}\text { Restorations and ex- } \\
\text { tractions }\end{array}$ & $\begin{array}{c}\text { Place intracoronal (resin composite) } \\
\text { bonded with self-etching primer adhe- } \\
\text { sive or extracoronal restorations (stain- } \\
\text { less steel crowns). Consider orthodontic } \\
\text { outcomes post extraction }\end{array}$ \\
\hline Maintenance & $\begin{array}{c}\text { Monitor margins of restorations for PEB } \\
\text { Consider full coronal coverage restora- } \\
\text { tions in the long-term }\end{array}$ \\
\hline
\end{tabular}

Table 1 


\section{Conclusion}

A comprehensive assessment of the affected teeth, including clinical and radiological investigations, will determine the extent and severity of the condition. Referral for an orthodontic and/or endodontic opinion may be necessary in severe cases of MIH.

\section{Bibliography}

1. Krämer N., et al. "Bonding strategies for MIH-affected enamel and dentin". Dental Materials 34.2 (2018): 331-340.

2. Dixit UB and Joshi AV. "Efficacy of intraosseous local anesthesia for restorative procedures in molar incisor hypomineralization-affected teeth in children". Contemporary Clinical Dentistry 9.2 (2018): S272.

3. Bhandari R., et al. "Concealment effect of resin infiltration on incisor of Grade I molar incisor hypomineralization patients: An In vivo study". Journal of Conservative Dentistry: JCD 21.4 (2018): 450.

4. Wuollet E., et al. "The association between molar-incisor hypomineralization and dental caries with socioeconomic status as an explanatory variable in a group of finnish children". International Journal of Environmental Research and Public Health 15.7 (2018): 1324.

5. Giuca MR., et al. "Investigation of Clinical Characteristics and Etiological Factors in Children with Molar Incisor Hypo mineralization". International Journal of Dentistry (2018).

6. De Aguiar Grossi J., et al. "Glass hybrid restorations as an alternative for restoring hypomineralized molars in the ART model". BMC Oral Health 18.1 (2018): 65.

\section{Assets from publication with us}

- Prompt Acknowledgement after receiving the article

- Thorough Double blinded peer review

- Rapid Publication

- Issue of Publication Certificate

- High visibility of your Published work

Website: www.actascientific.com/

Submit Article: www.actascientific.com/submission.php

Email us: editor@actascientific.com

Contact us: +919182824667

Citation: Megha Chawla., et al. "Molar Incisor Hypomineralization - Review and Recommendations for Management”. Acta Scientific Dental Sciences 4.3 (2020): 13-15. 